\title{
Guia de Atividade Física para a População Brasileira
}

\section{Physical Activity Guidelines for the Brazilian Population}

\begin{abstract}
AUTORES
Pedro Curi Hallal ${ }^{1}$ (D)

Daniel Umpierre ${ }^{2}$ (D)

1 Universidade Federal de Pelotas, Programa de Pós-Graduação em Educação Física, Pelotas, Rio Grande do Sul, Brasil.

2 Universidade Federal do Rio Grande do Sul, Departamento de Saúde Coletiva, Porto Alegre, Rio Grande do Sul, Brasil.
\end{abstract}

\section{CONTATO}

Universidade Federal de Pelotas, Programa de Pós-graduação em Epidemiologia.

Rua Marechal Deodoro 1160 - III piso, Centro, Pelotas, Rio Grande do Sul, Brasil

CEP: 96020-220.

DOI

$10.12820 /$ rbafs.26e0211

\section{(cc) BY}

Este trabalho está licenciado com uma Licença Creative Commons - Atribuição 4.0 Internacional.
O Brasil tem protagonismo internacional na área de atividade física e saúde. O país possui uma Sociedade Científica, um periódico e um congresso que tratam especificamente do tema, sendo todos mais antigos que seus equivalentes no âmbito global ${ }^{1}$. O país inclusive sediou o Congresso Internacional de Atividade Física e Saúde em 2014. A política brasileira de promoção da atividade física foi destaque na Série de Atividade Física do Lancet em $2012^{2}$. O país possui sistemas de monitoramento do nível de atividade física de adolescentes e adultos ${ }^{3,4}$ e foi recentemente classificado como o quarto país do mundo no ranking da pesquisa em atividade física ${ }^{5}$.

Apesar de todo esse engajamento na área, o Brasil ainda não possuía recomendações de atividade física para sua população. Iniciativas anteriores já haviam sido planejadas, tanto no âmbito do Governo Federal quanto no âmbito de sociedades científicas, mas não se materializaram. Em 2019, o Ministério da Saúde firmou um termo de execução descentralizada com a Universidade Federal de Pelotas para a produção do Guia de Atividade Física para a População Brasileira. Desde a concepção inicial do projeto, a Sociedade Brasileira de Atividade Física e Saúde foi convidada a ter protagonismo no processo, visto que possuía um grupo de trabalho em andamento exatamente para lidar com esse tema.

O trabalho foi conduzido num período de dois anos, por meio de uma parceria da academia, representada por pesquisadores de dezenas de Universidades brasileiras, com o poder público, representada pela equipe técnica da Coordenação Geral de Promoção da Atividade Física e Ações Intersetoriais (CGPROFI). O projeto contou com um Comitê Científico, composto pelo Coordenador Geral do Projeto, representantes de cada região do Brasil, representação da Sociedade Brasileira de Atividade Física e Saúde, representação de um pesquisador brasileiro que atuou na elaboração das Recomendações de Atividade Física da Organização Mundial da Saúde, representação da CGPROFI e representação da Organização Panamericana de Saúde.

Nas primeiras reuniões, o Comitê Científico deliberou sobre alguns preceitos básicos do Guia: (a) o material seria voltado à população brasileira, e não aos pesquisadores, utilizando uma linguagem acessível ao público não especializado; (b) o Guia seria estruturado por ciclos da vida; (c) o Guia abordaria os diferentes contextos nos quais a atividade física é praticada. Após essas deliberações, o Comitê formou oito grupos de trabalho temático, que acabaram gerando os capítulos finais do documento (Quadro 1).

Foram abertos processos de seleção pública para escolher os coordenadores de cada grupo de trabalho e, também, os participantes desses grupos, respeitando critérios técnicos estabelecidos pelo Comitê Científico. Todos os grupos de trabalho conduziram revisões da literatura e consultas públicas 
Quadro 1 - Grupos de trabalho que compuseram o Guia de Atividade Física para a População Brasileira.

\begin{tabular}{|c|}
\hline Conceitos e Definições na Área de Atividade Física \\
\hline Crianças de 0-5 anos \\
Jovens de 6-17 anos \\
Adultos de 18-64 anos \\
Adultos de 65 anos ou mais \\
Gestantes e mulheres no pós-parto \\
Pessoas com Deficiência \\
Educação Física Escolar \\
\hline
\end{tabular}

para confecção dos textos, que posteriormente foram revisados e compatibilizados, tanto pelo Comitê Científico quanto pelo Ministério da Saúde.

O Guia de Atividade Física para a População Brasileira está composto por oito capítulos que apresentam os conceitos e contextos relacionados à atividade física, bem como recomendações organizadas para grupos específicos e ciclos de vida. Além disso, o Guia é acompanhado por um documento de recomendações para gestores e profissionais da saúde, o qual aborda ações para difusão, implementação e monitoramento a partir do Guia, contextualizando seu uso para a atuação baseada em princípios do Sistema Único de Saúde (SUS). A estratégia de disseminação do Guia também foi cuidadosamente elaborada, incluindo a distribuição nacional a diversos órgãos e atores públicos e às secretarias estaduais e municipais de saúde. De forma inédita, o Guia está disponibilizado em versão de áudio e em Braile, promovendo o acesso às pessoas com deficiência, e possui versões digitais em espanhol e inglês, facilitando o acesso à comunidade de estrangeiros e refugiados que residem no Brasil e usam o SUS, possibilitando que outros países se inspirem na experiência brasileira.

Lamentavelmente, o lançamento oficial, realizado no dia 29 de junho de 2021, alijou a participação das dezenas de pesquisadores que atuaram na elaboração do Guia, em atitude de evidente retaliação ao fato de que o Coordenador Geral do projeto é crítico à postura brasileira no enfrentamento da pandemia de corona- vírus e havia sido depoente na Comissão Parlamentar de Inquérito que investiga as ações e omissões no enfrentamento da pandemia no Brasil na semana anterior ao lançamento do Guia. Como prova definitiva dessa perseguição, o lançamento já havia sido programado anteriormente, e contava com a confirmação da presença dos pesquisadores. Ciência e democracia não combinam com perseguição política.

É importante colocarmos o Guia em perspectiva e salientarmos que este é um documento histórico, fruto do sonho de muitas pessoas, mas que - em essência - visa promover a prática de atividade física da população. Por isso, é válido considerarmos o Guia como um marco importante para a área da atividade física e saúde, porém, não como um ponto de chegada. Ao contrário, o Guia deve compor e estimular outras estratégias para a promoção de saúde e bem-estar das pessoas. Frente às desigualdades da população brasileira, nosso horizonte ainda mostra diversos desafios para que a atividade física seja oportunizada de forma ampla para todas as pessoas. O Guia, portanto, nos convida a mais trabalho: participativo, colaborativo e ético.

\section{Referências}

1. Hallal PC, Reis RR. 5० Congresso Internacional de Atividade Física e Saúde Pública no Brasil: daqui pra frente tudo será diferente? Rev Bras Ativ Fís Saúde. 2014; 19:141.

2. Malta DC, Barbosa da Silva J. Policies to promote physical activity in Brazil. Lancet 2012;380:195-6.

3. Malta DC, Iser BP, Santos MA, Andrade SS, Stopa SR, Bernal RT, et al. Lifestyles in Brazilian capitals according to the National Health Survey and the Surveillance System for Protective and Risk Factors for Chronic Diseases by Telephone Survey (Vigitel), 2013. Rev Bras Epidemiol. 2015;18 Suppl 2:68-82.

4. Hallal PC, Knuth AG, Cruz DK, Mendes MI, Malta DC. Prática de atividade física em adolescentes brasileiros. Cien Saude Colet 2010;15 Suppl 2:3035-42.

5. Global Observatory for Physical Activity: Brazil Country Card. https://new.globalphysicalactivityobservatory.com/ card/?country=BR. (Acessado em 05 de julho de 2021).

\section{Como citar este artigo:}

Hallal PC, Umpierre D. Guia de Atividade Física para a População Brasileira. Rev Bras Ativ Fís Saúde. 2021;26:e0211. DOI: 10.12820/rbafs. $26 e 0211$ 